Altruistic and Joy-of-Giving Motivations in Charitable Behavior Author(s): David C. Ribar and Mark O. Wilhelm

Source: The Journal of Political Economy, Vol. 110, No. 2 (April 2002), pp. 425-457

Published by: The University of Chicago Press

Stable URL: http://www.jstor.org/stable/10.1086/338750

Accessed: $17 \overline{/ 06 / 201107: 39}$

Your use of the JSTOR archive indicates your acceptance of JSTOR's Terms and Conditions of Use, available at http://www.jstor.org/page/info/about/policies/terms.jsp. JSTOR's Terms and Conditions of Use provides, in part, that unless you have obtained prior permission, you may not download an entire issue of a journal or multiple copies of articles, and you may use content in the JSTOR archive only for your personal, non-commercial use.

Please contact the publisher regarding any further use of this work. Publisher contact information may be obtained at http://www.jstor.org/action/showPublisher?publisherCode=ucpress.

Each copy of any part of a JSTOR transmission must contain the same copyright notice that appears on the screen or printed page of such transmission.

JSTOR is a not-for-profit service that helps scholars, researchers, and students discover, use, and build upon a wide range of content in a trusted digital archive. We use information technology and tools to increase productivity and facilitate new forms of scholarship. For more information about JSTOR, please contact support@jstor.org. 


\section{Altruistic and Joy-of-Giving Motivations in Charitable Behavior}

\section{David C. Ribar}

George Washington University

Mark O. Wilhelm

Indiana University Purdue University Indianapolis

This study theoretically and empirically examines altruistic and joyof-giving motivations underlying contributions to charitable activities. The theoretical analysis shows that in an economy with an infinitely large number of donors, impurely altruistic preferences lead to either asymptotically zero or complete crowd-out. The paper then establishes conditions on preferences that are sufficient to yield zero crowd-out in the limit. These conditions are fairly weak and quite plausible. An empirical representation of the model is estimated using a new 1986-92 panel of donations and government funding from the United States to 125 international relief and development organizations. Besides directly linking sources of public and private support, the econometric analysis controls for unobserved institution-specific factors, institution-specific changes in leadership, year-to-year changes in need, and expenditures by related organizations. The estimates show little evidence of crowd-out from either direct public or related private

Earlier versions of this paper titled "An Empirical Test of Altruistic and Joy-of-Giving Motivations in Charitable Behavior" were presented at the 1995 American Economic Association meetings in Washington, D.C., and the 1995 meetings of the Association for Research on Nonprofit Organizations and Voluntary Action in Cleveland. We thank Jennjou Chen, Hongshu Han, Dan Henry, Tammy Kolbe, Rob Poulton, Randy Sherrod, and Yinghui Zhu for excellent research assistance and Rick Bond, Tom Gresik, Norm Swanson, Al Slivinski, Rich Steinberg, the editor, and an anonymous referee as well as seminar participants at George Washington, Indiana University-Purdue University at Indianapolis, Indiana, and Penn State for helpful comments and discussions. We also wish to thank staff at the Center for Research on the Epidemiology of Disasters (University College London-Brussels) and the U.S. Agency for International Development for providing various data and answering questions.

[Journal of Political Economy, 2002, vol. 110, no. 2]

(C) 2002 by The University of Chicago. All rights reserved. 0022-3808/2002/11002-0008 $\$ 10.00$ 
sources. Thus, at the margin, donations to these organizations appear to be motivated solely by joy-of-giving preferences. In addition to addressing the basic question of motives behind charitable giving, the results help explain the existing disparity between econometric and experimental crowd-out estimates.

\section{Introduction}

A fundamental question in public economics concerns the motivations underlying voluntary donations to charitable activities and other forms of charitable behavior. One hypothesis is that donors are motivated by altruistic concern over the well-being of the recipients of charity. While reasonable on its face, this hypothesis implies that recipients' well-being is a public good among other individuals who are similarly motivated (Hochman and Rodgers 1969; Warr 1982; Roberts 1984) and that charitable contributions are subject to the strong neutrality results of publicgoods models. The neutrality results include complete dollar-for-dollar crowd-out of private contributions when similarly directed government funding increases, no change in aggregate donations when income is redistributed among contributors, and a decline in the percentage of the population who contribute as the size of the population grows (see, e.g., Sugden 1982; Warr 1982, 1983; Roberts 1984; Andreoni 1988). Noting that people may derive private enjoyment from the act of giving itself, several authors have proposed combining a "joy-of-giving" motive with altruism to create a model of impure altruism (Cornes and Sandler 1984, 1994; Steinberg 1987; Andreoni 1989, 1990). The attractiveness of the impurely altruistic model is that it is thought to avoid the strong neutrality results of purely altruistic models. ${ }^{1}$

Empirical research has used a variety of sources including individuallevel cross-section, aggregate time-series, and experimental data to measure the extent of crowd-out and interpreted the resulting estimates as providing evidence about the relative strengths of the impurely altruistic model's two components. Unfortunately, the alternative empirical approaches have generated divergent findings. On the one hand, econometric crowd-out analyses of cross-section tax return and survey data suggest a weak to moderate altruistic component in giving (see Stein-

\footnotetext{
${ }^{1}$ Theorists have examined other extensions that weaken the neutrality results. For instance, Bergstrom, Blume, and Varian (1986) showed that the neutrality results may not obtain if some people are at corner solutions at which they donate nothing. Their result was contradicted, however, by Andreoni (1988), who found that crowding out is asymptotically complete as the number of donors rises. A small crowd-out response (more accurately, an income effect) will also occur if an increase in government expenditures is financed by an increase in taxes, which reduces disposable income available for private giving.
} 
berg's [1991] review). On the other hand, public-goods experiments (Andreoni 1993; Bolton and Katok 1998) and historical accounts of the decline in private social welfare contributions that accompanied the rise in publicly funded poverty relief in the United States during the 1930s (Roberts 1984) provide evidence of sizable crowd-out effects and a strong altruistic component. Researchers have not been able to reconcile the stark differences in results and have instead focused on the methodological shortcomings of each approach. Little consideration has been given to the possibility that the cross-section, time-series, and experimental results are all essentially correct and consistent with a more careful analysis of the impurely altruistic model.

This study attempts to provide a positive reconciliation. It first conducts a theoretical analysis that shows that impurely altruistic models, which predict incomplete crowd-out effects among individual or small groups of donors (as in the experimental studies), may well produce asymptotically zero crowd-out effects as the number of donors becomes large (as in the cross-section econometric studies). The analysis also shows that asymptotically complete crowd-out may occur under a reasonable set of circumstances. However, asymptotically incomplete crowdout, which impurely altruistic models are widely thought to predict, occurs only under knife-edge conditions. Which of the likely asymptotic predictions, complete or zero crowd-out, actually obtains depends on the relative strength of two opposing forces. First, when individuals' altruistic motives are held constant, crowd-out becomes increasingly strong as the number of donors grows. Second, however, altruism becomes a weaker motive for each individual donor to the extent that additional donors provide more of the public good and each donor's marginal utility of the public good declines. Somewhat unexpectedly, for a wide class of utility functions-including those typically used by economists - the marginal utility of the public good declines fast enough so that the second force overwhelms the first. If real-world preferences fall within this class of utility functions, econometric analyses of situations with many donors would find zero crowd-out. ${ }^{2}$

The study then extends its theoretical model to include several features relevant to empirical work, most importantly by considering gifts to multiple organizations that provide similar, though slightly differentiated, charitable services. ${ }^{3}$ The extended model is estimated using a

\footnotetext{
${ }^{2}$ There have been several interesting theoretical extensions of the impurely altruistic model (e.g., Dasgupta and Itaya 1992; Ihori 1992; Vicary 1997), but none of them have attempted to explain the very low econometric estimates of crowd-out or the disparity between these estimates and the experimental evidence.

${ }^{3}$ Theoretical analyses by Bergstrom et al. (1986) and Rose-Ackerman (1986) considered private contributions to multiple charitable goods. We are unaware of any empirical investigations of such models.
} 
new 1986-92 panel of private donations and government funding from the United States to 125 international relief and development organizations. Because it is unlikely that U.S. residents will materially benefit from their gifts to these organizations, we can directly interpret our tests for public-good crowd-out in these data as tests for altruistic preferences. ${ }^{4}$ Besides the measures of public and private support, the data include information on the organizations' fund-raising, administrative overhead, service activities, regions of operation, and leadership. With these data, the study conducts crowd-out tests while simultaneously addressing a number of important statistical issues.

First, by using administrative data with the organization as the unit of analysis, we are able to precisely measure and match private and public financing to provide the same public good. Second, the panel nature of the data allows us to include fixed effects in our econometric models to mitigate possible biases from unobservable organization-specific factors that may affect both public and private support. Third, we use the activity and region data to create time-varying controls for changes in need among the organizations' beneficiaries. We also use these data to construct measures of similarity between the outputs of organizations, which, in turn, enable us to examine whether donations to one organization are crowded out by expenditures from other organizations with similar program agendas. Previous studies have been criticized for failing to include adequate controls for need and other types of support. Finally, we use the data on changes in the organizations' chief executives to control for time-varying leadership effects. They are intended to mitigate biases caused by internal shifts within organizations that may generate comovements in contributions and government support (e.g., a new leader who alters the organization's mission in a way that induces additional support from donors and the government).

The study's empirical results show little evidence of crowd-out from either direct public or related private sources. Thus, at the margin, charitable contributions appear to reflect joy-of-giving motivations. The empirical findings are robust to the econometric issues we have just described and to alternative assumptions regarding the amount of in-

\footnotetext{
${ }^{4}$ Most previous research has considered contributions to domestic religious, educational, cultural, health, and human service nonprofits. It is probable that contributions to these groups are at least partially motivated by donors' preferences for their own actual or potential future consumption of the goods and services provided by the organizations and, consequently, that tests of public-good crowd-out based on these data do not entirely reflect preferences for altruism (for supporting evidence, see Biddle [1992] and Salamon [1992]). In an earlier paper (Ribar and Wilhelm 1995), we examined state-level data on contributions to a small set of international relief and development organizations but focused on tax price and income effects and configured the data so as to eliminate possible biases from government crowd-out; Khanna, Posnett, and Sandler (1995) also examined a small number of U.K.-based international relief and development organizations.
} 
formation donors might reasonably be expected to possess before making their contribution decisions.

The remainder of the paper is organized as follows. Section II examines the asymptotic properties of impurely altruistic models and describes extensions of the model for purposes of estimation. Section III reviews previous empirical research. The data for estimation are described in Section IV. Section V describes the econometric methodology and reports our empirical findings. Conclusions as well as additional implications of our results are presented in Section VI.

\section{The Model}

\section{A. The Limits of Impure Altruism: Asymptotic Crowd-Out}

Consider an impurely altruistic model of charitable giving with $N$ donors in which the $i$ th donor's utility is defined over her own consumption, $c_{i}$, the utility of a representative beneficiary served by charitable institution $\mathcal{H}$, and the size of $i$ 's contribution to $\mathcal{H}, h_{i}$. The second preference component is a public good because other donors also care about the well-being of those whom the charity serves. Unable to measure this well-being directly, we assume that donors' concerns can be adequately captured by the expenditures $\mathcal{H}$ makes on services for the beneficiaries. We further simplify by assuming that the organization's expenditures on services exactly equal the contributions it receives (this will be subsequently relaxed). The third component of utility arises from the private joy of giving or "warm glow" $i$ experiences when making her gift.

The $i$ th donor selects nonnegative levels of consumption and contributions to maximize a utility function

$$
U=U_{i}\left(c_{i}, \tilde{H}, h_{i}\right)
$$

subject to the budget constraint

$$
c_{i}+h_{i}=y_{i}-\tau_{i}
$$

where $y_{i}$ is income and $\tau_{i}$ is a lump-sum tax paid to the government. Donor $i$ 's contribution combines with the gifts of others, $H_{-i}$, and funding from the government, $H_{G}$, to form total contributions to the institution, $\tilde{H}$ :

$$
\tilde{H}=h_{i}+H_{-i}+H_{G}=H+H_{G} .
$$

The budget constraint (2) can be rewritten by adding $H_{-i}+H_{G}$ to both sides of the equation

$$
c_{i}+\tilde{H}=Z_{i}, \quad Z_{i} \equiv y_{i}-\tau_{i}+H_{-i}+H_{G},
$$


where $Z_{i}$ can be interpreted as the donor's "social income." We shall sometimes use $x_{i}=y_{i}-\tau_{i}$ to represent $i$ 's disposable income.

Using (3) to substitute for $h_{i}$ and (4) to represent the budget constraint, we can rewrite the donor's maximization problem in terms of $\tilde{H}$. This yields the interior first-order condition

$$
\begin{gathered}
-U_{i c}\left\lfloor Z_{i}-\tilde{H}, \tilde{H}, \tilde{H}-\left(H_{-i}+H_{G}\right)\right\rfloor+U_{i H}\left\lfloor Z_{i}-\tilde{H}, \tilde{H}, \tilde{H}-\left(H_{-i}+H_{G}\right)\right\rfloor \\
+U_{i h}\left\lfloor Z_{i}-\tilde{H}, \tilde{H}, \tilde{H}-\left(H_{-i}+H_{G}\right)\right\rfloor=0 .
\end{gathered}
$$

The first-order condition leads to implicit demand functions for the total provision of the public good,

$$
\tilde{H}^{*}=q_{i}\left(Z_{i}, H_{-i}+H_{G}\right)
$$

to which the donor's optimal contribution is

$$
h_{i}^{*}=q_{i}\left(Z_{i}, H_{-i}+H_{G}\right)-H_{-i}-H_{G}
$$

with the corresponding differentials

$$
\begin{aligned}
d h_{i}^{*}= & q_{i 1}\left(d y_{i}-d \tau_{i}+d H_{-i}+d H_{G}\right)+q_{i 2}\left(d H_{-i}+d H_{G}\right) \\
& -d H_{-i}-d H_{G} .
\end{aligned}
$$

Andreoni $(1989,1990)$ has provided the intuition relating notions of altruism and the joy of giving to the partial derivatives of $q_{i}(\cdot, \cdot)$. The partial derivatives $q_{i 1}$ and $q_{i 2}$ together reflect the altruistic and joy-ofgiving components of benevolence. If the donor is motivated purely by altruism, then $q_{i 1}>0$ and $q_{i 2}=0$, and changes in the contributions of others, $d H_{-i}+d H_{G}$, generate the largest amount of crowd-out. In contrast, if the donor is motivated only by the joy of giving, then $q_{i 1}+$ $q_{i 2}=1$, and changes in the contributions of others have no effect on giving. Finally, the gifts of impure altruists are influenced by both components such that $q_{i 1}>0, q_{i 2}>0$, and $q_{i 1}+q_{i 2}<1 .^{5}$

To examine how aggregate private gifts respond to government fund-

${ }^{5}$ The last inequality presumes normality of own consumption and donations with respect to the contributions of others $\left(H_{-i}+H_{G}\right)$. Cornes and Sandler (1994) have provided a detailed analysis of the comparative statics of the impure altruism model and have considered the theoretical possibilities of crowd-in (in the present notation, $q_{i 1}+q_{i 2}>1$ ) and super-crowd-out $\left(q_{i 1}+q_{i 2}<0\right)$. Our subsequent discussion of crowding out as the number of impure altruists increases holds for either of these two cases. That is, we need not assume normality. However, the extension of our results to heterogeneous agents will require that $q_{i 1}+q_{i 2}$ be bounded. 
ing, we follow Sugden (1982) and Andreoni $(1988,1989,1990)$ by summing equation (8) over all donors and solving for $d H$ :

$$
\begin{aligned}
d H= & \frac{\sum_{i=1}^{N} \frac{q_{i 1}}{q_{i 1}+q_{i 2}}\left(d y_{i}-d \tau_{i}\right)-\left[\sum_{i=1}^{N} \frac{1-\left(q_{i 1}+q_{i 2}\right)}{q_{i 1}+q_{i 2}}\right] d H_{G}}{1+\sum_{i=1}^{N} \frac{1-\left(q_{i 1}+q_{i 2}\right)}{q_{i 1}+q_{i 2}}} \\
= & \frac{\sum_{i=1}^{N} \frac{q_{i 1}}{q_{i 1}+q_{i 2}}\left(d y_{i}-d \tau_{i}\right)}{1+\sum_{i=1}^{N} \frac{1-\left(q_{i 1}+q_{i 2}\right)}{q_{i 1}+q_{i 2}}}+\kappa_{N} d H_{G},
\end{aligned}
$$

where

$$
\kappa_{N} \equiv \frac{-A_{N}}{1+A_{N}}, \quad A_{N} \equiv \sum_{i=1}^{N} \frac{1-\left(q_{i 1}+q_{i 2}\right)}{q_{i 1}+q_{i 2}},
$$

and $\kappa_{N}$ represents the degree of crowd-out. As $N \rightarrow \infty$, the degree of crowd-out depends on limiting properties of the series $A_{N}$, which appears in both the numerator and denominator of $\kappa_{N}$.

Proposition 1. In an impurely altruistic model of private contributions to a pure public good, as $N \rightarrow \infty$, the crowd-out of private contributions in response to changes in government funding is asymptotically (i) zero if $A_{N}$ converges to zero; (ii) dollar-for-dollar, or "complete," if $A_{N}$ is infinite in the limit; or (iii) between zero and dollar-for-dollar, or "incomplete," if $A_{N}$ converges to any nonzero finite number.

The series $A_{N}$ converges or diverges according to whether and how fast $q_{i 1}+q_{i 2} \rightarrow 1$. This in turn depends on the functional form of the underlying preference specification. To examine the properties of the model more carefully, consider a version of the model in which donors have identical preferences and disposable incomes so that $q_{i}(\cdot, \cdot)=$ $q(\cdot, \cdot)$ for all $i$ and $A_{N}=N\left[1-\left(q_{1}+q_{2}\right)\right] /\left(q_{1}+q_{2}\right){ }^{6}$

It will also be convenient to refer to the rate at which $q_{1}+q_{2} \rightarrow 1$ as the minimum number $\phi$ for which $\lim _{N \rightarrow \infty}\left(q_{1}+q_{2}-1\right) / N^{\phi}=a, 0<$ $|a|<\infty$. In a minor deviation from standard notation, we write this as $q_{1}+q_{2}-1=O\left(N^{\phi}\right)$. Thus, if $q_{1}+q_{2} \rightarrow 1$ faster than rate $N, \phi<-1$. If $q_{1}+q_{2} \rightarrow 1$ at exactly rate $N, \phi=-1$. If $q_{1}+q_{2} \rightarrow 1$ slower than rate $N$, $\phi>-1$; note that the case in which $q_{1}+q_{2}$ converges to a number other than one is included in this range $(\phi=0)$. When $\phi>-1$, we shall say that altruism remains "effective" at the margin. With this notation, the representative donor version of proposition 1 is as follows.

\footnotetext{
${ }^{6}$ Extending the model to incorporate donors with heterogeneous preferences and incomes is straightforward and does not change the main results.
} 
Corollary 1.1. If donors have identical preferences and disposable incomes, then crowd-out is asymptotically (i) zero if $\phi<-1$, (ii) complete if $\phi>-1$, or (iii) incomplete if $\phi=-1$.

Proposition 1 and corollary 1.1 are stated in terms of changes in government funding without corresponding changes in the government's tax revenues. To examine a change in the government's provision of the public good that is financed by additional lump-sum taxes on the donors and for comparability with previous analyses, corollary 1.2 considers a balanced-budget change in government funding.

Corollary 1.2. If donors have identical preferences and disposable incomes and $d H_{G}=\sum d \tau_{i}=N d \tau$, where $d \tau$ is the representative donor's lump-sum tax change, then the balanced-budget asymptotic crowd-out (i) equals $-\lim _{N \rightarrow \infty} q_{1}$ if $\phi<-1$, (ii) is complete if $\phi>-1$, or (iii) is incomplete but of magnitude $-\left(A+\lim _{N \rightarrow \infty} q_{1}\right) /(1+A)$, where $\lim _{N \rightarrow \infty} A_{N}=A$, if $\phi=-1$.

The empirical implications of this result differ from those of corollary 1.1 only in that tax-induced income effects lead to some crowd-out in case i. Corollaries 1.1 and 1.2 both imply that in an economy with a large number of donors, a test for effective altruistic motives at the margin amounts to a test for complete crowd-out. This is unlike models with few donors in which appropriate tests for altruism must be based on both crowd-out and income effects. ${ }^{7}$

The intuition behind case $\mathrm{i}$ in proposition 1 and the corollaries is straightforward: if in the limit each donor behaves like a pure joy-ofgiver, there is no crowd-out beyond what might be caused by tax-induced income effects. ${ }^{8}$ In contrast, it is somewhat surprising that in case ii crowd-out is asymptotically complete even though each donor's altruism is impurely mixed with a joy-of-giving motive. The intuition is similar to that offered by Andreoni (1989) to explain incomplete crowd-out when a single impure altruist is taxed one dollar so that the government can fund a one dollar increase in the public good. Because the public provision is not a perfect substitute for her own gift, the impure altruist does not completely neutralize the additional dollar provided by the government. Thus the net effect of the government's action is a fraction of a dollar increase in the public good. A second impure altruist would regard this fraction of a dollar as an exogenous increase in the public good and neutralize another fraction of the increase. In the limit, as each additional impure altruist neutralizes a fraction of the net change

${ }^{7}$ Altonji, Hayashi, and Kotlikoff (1997) estimated models of altruism within the family in which crowd-out was not dollar-for-dollar because of the income effect induced by the change in social income.

${ }^{8} \mathrm{~A}$ special case of this result for fixed coefficient-shaped preferences can be generated by extending Mulligan's (1997, pp. 314-16) analysis to ask what happens to crowd-out as $N$ increases. 
left by the others, the government's initial attempt to increase the public good is entirely neutralized. ${ }^{9}$ Case iii shows that asymptotically incomplete crowd-out is a knife-edge case. It can occur only when $q_{1}+q_{2} \rightarrow$ 1 exactly at rate $N$.

\section{B. Sufficient Conditions for Asymptotically Zero Crowd-Out}

In this subsection, we characterize a class of utility functions that lead to asymptotically zero crowd-out. We assume that $U\left(c_{i}, \tilde{H}, h_{i}\right)$ is concave, is twice continuously differentiable, and has strictly positive first derivatives, and $U_{H}\left(c_{i}, h_{i}, h_{i}\right)<\infty$ for $h_{i}>0$. None of these assumptions is particularly strong. Also, we assume that, for all levels of the public good $\tilde{H}, U_{c c}, U_{h c}$, and $U_{h h}$ are finite and $U_{c c}-2 U_{h c}+U_{h h}$ is bounded away from zero. This implies that the second partial derivatives with respect to the private goods in the model neither vanish nor diverge as the amount of the public good increases. These, too, are fairly weak assumptions because even though increases in the public good provided by others increase an individual's social income, they do not relax the private income constraint on $c_{i}$ and $h_{i}$. More important is the following definition, which describes a donor who would make a contribution regardless of her marginal utility of the public good.

Definition. If $U_{h}\left(x_{i}, \tilde{H}, 0\right)-U_{c}\left(x_{i}, \tilde{H}, 0\right) \geq \Delta>0$, we say that the joyof-giving motive is strictly operative at $\tilde{H}$.

This definition, which requires that the utility gain via the joy of giving from the first dollar contributed not vanish, is slightly stronger than the usual notion of an operative motive that would permit a positive but vanishing utility gain. The definition is not unreasonable; it simply formalizes the idea of a finite, private gain from giving that is independent of the level of the public good.

We then have the following proposition (see App. A).

Proposition 2. If donors have identical preferences and disposable

\footnotetext{
${ }^{9}$ Similar asymptotic arguments can be applied to results from other papers. For example, Andreoni (1989) considered a balanced-budget change in government funding in which only one person pays the necessary lump-sum tax. The change in total (public plus private) provision of the public good is unaffected by this tax increase in the limit as $N \rightarrow \infty$ (see his eq. 6) unless the donors are all pure joy-of-givers. In this model and ours, a finite change in public provision can be financed with asymptotically small increases in taxes on each individual collected from a growing pool of individuals. In contrast, Andreoni (1990) considered a change in public provision that implicitly grows with the number of donors. Rearranging the equation for the change in total provision of the public good in his proposition $3 \mathrm{a}$, one can show that the change in private provision equals a weighted average of the changes in individuals' taxes minus the change in public provision. As the change in public provision grows with the number of donors, the weighted average term becomes relatively negligible. Thus, in the limit, the change in private provision equals the negative of the change in public provision.
} 
incomes, preferences follow the assumptions above, and the joy-of-giving motive is strictly operative, then crowd-out is asymptotically zero.

The essence of this result is that if very large amounts of the public good are being provided and utility is concave, additional increases in government support have negligible effects on individuals' first-order conditions and, consequently, on their optimal gifts. In a large economy, a strictly operative joy-of-giving motive guarantees a large amount of the public good because total provision grows with the number of donors.

This result is interesting because it explains the seemingly contradictory evidence on crowd-out from the experimental and econometric analyses. For the experimental studies in which $N$ is typically very small, the model predicts a relatively large degree of crowd-out unless individuals are characterized by nearly pure joy-of-giving preferences. In contrast, the econometric studies examine gifts made to organizations and activities that draw support from large bases of donors. Our asymptotic results are consistent with these studies' findings of small to negligible crowd-out. ${ }^{10}$

To illustrate the theoretical results, consider a Cobb-Douglas utility function

$$
U=\left(1-\eta_{1}-\eta_{2}\right) \ln \left(c_{i}\right)+\eta_{1} \ln (\tilde{H})+\eta_{2} \ln \left(h_{i}\right) .
$$

This specification satisfies our initial assumptions and has a strictly operative joy-of-giving motive $\left(U_{h}=\infty\right.$ when $\left.h_{i}=0\right)$. Solving for $q_{i 1}$ and $q_{i 2}$ yields

$$
\begin{aligned}
q_{i 1}+q_{i 2} & =\frac{\partial \tilde{H}^{*}}{\partial Z_{i}}+\frac{\partial \tilde{H}^{*}}{\partial\left(H_{-i}+H_{G}\right)} \\
& =\frac{\left[\left(1-\eta_{1}-\eta_{2}\right) /\left(c_{i}^{*}\right)^{2}\right]+\left[\eta_{2} /\left(h_{i}^{*}\right)^{2}\right]}{\left[\left(1-\eta_{1}-\eta_{2}\right) /\left(c_{i}^{*}\right)^{2}\right]+\left[\eta_{1} /\left(\tilde{H}^{*}\right)^{2}\right]+\left[\eta_{2} /\left(h_{i}^{*}\right)^{2}\right]} .
\end{aligned}
$$

Hence, $q_{i 1}+q_{i 2}-1=O\left(N^{-2}\right)$ because $\tilde{H}^{*}=N h_{i}^{*}$ and crowd-out will be asymptotically zero.

${ }^{10}$ There is a well-known literature that focuses on free riding with an experimentally induced public good that increases subjects' payoffs. A striking result from this literature-that there can be less free riding when the number of subjects is larger (see, e.g., Isaac, Walker, and Williams 1994) — can be explained via income effects in an impure altruism model. However, because crowd-out is not explicitly studied in these experiments, it is not clear what can be inferred about crowd-out from these results. For instance, it is easy to construct examples of preferences that produce free-riding results qualitatively similar to those of the experiments, but also with very unusual crowd-out predictions (i.e., large crowd-in).

Although we have focused on the conditions under which increases in the donor base lead to large $\tilde{H}$, our crowd-out results would also hold if $\tilde{H}$ became large because of a sizable increase in government expenditures. Thus the model potentially reconciles the historical evidence with contemporary econometric findings. 
Now modify the utility function so that $\tilde{H}$ and $h_{i}$ are perfect substitutes:

$$
U=(1-\eta) \ln \left(c_{i}\right)+\eta \ln \left(\tilde{H}+h_{i}\right),
$$

which leads to

$$
q_{i 1}=\frac{\eta}{2-\eta}, \quad q_{i 2}=\frac{1-\eta}{2-\eta} .
$$

Obviously, $q_{i 1}+q_{i 2} \rightarrow(2-\eta)^{-1}<1$ in the limit, and crowd-out is asymptotically complete.

A natural question is, How large does $N$ have to be before the asymptotic results become relevant for practical purposes? As an illustration, consider balanced-budget crowd-out as a function of $N$ using the preferences in $(10 \mathrm{a})$ and a relatively strong altruistic component to giving $\left(\eta_{1}=0.09\right.$ and $\left.\eta_{2}=0.01\right)$. Crowd-out drops quickly as $N$ increases: it is $70,37,15$, and 9 percent for $N=1,10,50$, and 100 donors, respectively. While the calculations are clearly sensitive to the assumptions regarding functional form and the levels of income and government expenditure, they suggest that the asymptotic results can become relevant even when the number of donors is fairly small.

\section{Other Extensions}

To introduce features of the model that we shall examine in the econometric analysis, we consider several extensions of the representative donor model. The most important is that we now assume that the impurely altruistic donor cares about the services provided by several charitable organizations to representative beneficiaries. For ease of exposition, consider two services, $Q$ and $R$, provided by two charitable institutions, $\mathcal{H}$ and $\mathcal{K}$. Accordingly, preferences can be written $U\left(c_{i}, Q\right.$, $\left.R, h_{i}, k_{i}\right)$, where $h_{i}$ and $k_{i}$ are nonnegative contributions to the two institutions. The budget constraint can be similarly modified: $c_{i}+h_{i}+$ $k_{i}=y_{i}-\tau_{i}$. Donations $h_{i}$ and $k_{i}$ combine with the gifts of others, $H_{-i}$ and $K_{-i}$, and funding from the government, $H_{G}$ and $K_{G}$, to form total contributions to the institutions, $\tilde{H}$ and $\tilde{K}$.

We assume that organization $\mathcal{H}$ concentrates its service expenditures on $Q$, whereas $\mathcal{K}$ divides its service expenditures between $Q$ and $R$. Specifically, the institutions use their total contributions to provide services according to

$$
Q=\lambda_{H} \tilde{H}+\beta \lambda_{K} \tilde{K}, \quad R=(1-\beta) \lambda_{K} \tilde{K},
$$

where $\lambda_{H}$ and $\lambda_{K}$ are efficiency parameters that indicate the amount of program services generated for each dollar contributed, and $\beta$ is the share of program expenditures $\mathcal{K}$ devotes to service $Q$. If $\beta=0$, there 
is no overlap in the provision of services; if $\beta=1$, the organizations offer exactly the same services.

The budget constraint can be rewritten by adding $H_{-i}+H_{G}$ and $K_{-i}+K_{G_{\tilde{C}}}$ to both sides of the equation and solving (12) to substitute for $\tilde{H}+\tilde{K}$ :

$$
\begin{aligned}
c_{i}+\tilde{H}+\tilde{K} & =c_{i}+P_{H} Q+\pi_{R} R=Z_{i}, \\
Z_{i} & \equiv y_{i}-\tau_{i}+H_{-i}+H_{G}+K_{-i}+K_{G},
\end{aligned}
$$

where $P_{H}=1 / \lambda_{H}, P_{K}=1 / \lambda_{K}$, and $\pi_{R}=\left(P_{K}-\beta P_{H}\right) /(1-\beta)$.The reciprocals of the $\lambda$ terms, $P_{H}$ and $P_{K}$, can be thought of as "efficiency prices." Because $\mathcal{H}$ provides only the service $Q$ the price of delivering one unit of $Q$ is simply $P_{H}$. The price of a unit of $R, \pi_{R}$, is a function of both prices and the degree of program overlap.

Repeating the type of analysis that led to (9) yields a demand for service $Q, Q^{*}=q\left(Z_{i}, H_{-i}+H_{G}, K_{-i}+K_{G}, P_{H}, P_{K}, \beta\right)$, which leads to the following comparative static equation for donations to $\mathcal{H}$ :

$$
\begin{aligned}
d H= & {\left[N-P_{H}\left(q_{1}+q_{2}\right)(N-1)\right]^{-1}\left\{P_{H} q_{1} \sum\left(d y_{i}-d \tau_{i}\right)\right.} \\
& -\left[1-P_{H}\left(q_{1}+q_{2}\right)\right] N d H_{G}-P_{H}\left(q_{1}+q_{3}\right) d K \\
& -\left[\beta \frac{P_{H}}{P_{K}}-P_{H}\left(q_{1}+q_{3}\right)\right] N d \tilde{K}+\left(\frac{\tilde{H}}{P_{H}}+P_{H} q_{4}\right) N d P_{H} \\
& \left.+P_{H}\left(q_{5}+\frac{\beta}{P_{K}^{2}} \tilde{K}\right) N d P_{K}+P_{H}\left(q_{6}-\frac{1}{P_{K}} \tilde{K}\right) d \beta\right\} .
\end{aligned}
$$

A similar expression can be derived for $d K$.

In equation (14), as in equation (9), government funding generates asymptotically zero or complete crowd-out depending on the functional form of utility. There are two other straightforward comparative static results to note. First, program expenditures of $\mathcal{K}$ crowd out contributions to $\mathcal{H}$ : the more similar $\mathcal{K}$ is to $\mathcal{H}$ (i.e., the closer $\beta$ is to one), the more its program expenditures crowd out contributions to $\mathcal{H}$. Second, each organization affects its own contributions and those to similar organizations through its service mix and efficiency. An increase in efficiency reduces the organization's own giving price, raises the implicit price of contributions to its "competitor," and consequently increases contributions.

Finally, to include a role for organizations' fund-raising activities, the model can be modified so that donors face fixed transaction costs in making their contribution decisions. We then posit that solicitation efforts lower these costs either by reducing a donor's time spent in gath- 
ering information about a charity or by minimizing the time and expense required to actually send a donation.

\section{Evidence from Previous Empirical Studies}

Previous empirical analyses based on cross-section data have uniformly found that government support does not completely crowd out private donations, with most estimates of the crowd-out effect falling in the range of zero to one-half. These studies have been criticized, however, for several methodological problems that may have biased their estimates away from findings of crowd-out.

Early studies relied on data gathered from tax returns or general surveys. As Steinberg (1991) pointed out, these studies were not able to precisely match specific types of private donations to related forms of government support. This meant that government support was effectively mismeasured and that estimates of its effects were biased toward zero. Kingma (1989) was the first to address the mismatch problem in his study of private and public contributions to National Public Radio stations. Subsequently, several other studies have adopted Kingma's methodology and examined private and public support on an organization-by-organization basis. These improvements notwithstanding, Kingma's research and the later studies continued to generate small estimates of crowd-out.

Studies have also been criticized for not addressing potential biases associated with relevant omitted variables (Andreoni 1993). Specifically, there could be unmeasured factors such as the reputation of a particular organization or a change in need among the set of potential beneficiaries that drive both private contributions and government support. Failure to account for these factors might lead to a spurious positive correlation between measures of private and public support (i.e., away from a finding of strong crowd-out). Recent studies by Khanna et al. (1995), Joulfaian and Power (1996), Payne (1998), Khanna and Sandler (2000), and Okten and Weisbrod (2000) have addressed the issue of omitted institution-specific factors by examining panel data for organizations and specifying their models to include organization fixed effects. In an effort to control for changes in need, Payne went a step further and specified her model to also include separate, general time effects for the regions served by each organization in her panel. Two well-known limitations of the fixed-effects approach are that it does not address biases from unmeasured factors that vary with individual organizations over time and that it may exacerbate biases associated with other statistical problems such as measurement error and simultaneity. Nevertheless, in the absence of direct measures of the relevant variables, fixed effects may be the only controls available. 
A final methodological problem is that government support might be an endogenous variable (Roberts 1993). In this case, bias would arise if either the unobserved determinants of government support and private contributions were correlated or private contributions were a direct determinant of government support (e.g., through matching requirements). Depending on the source of correlation, fixed effects could be used to address the first type of bias; however, they would not eliminate the second type of bias. A more appropriate remedy for endogeneity is to use an instrumental variables procedure. Payne (1998) and Khanna and Sandler (2000) have taken this approach, but both studies relied on questionable instruments. ${ }^{11}$ As a practical matter, it is hard to find instruments that predict government support and are convincingly unrelated to private contributions except through government support.

\section{Analysis Data Set}

The study examines contributions and expenditures from a 1986-92 panel of 125 international relief and development organizations. The financial data come primarily from the U.S. Agency for International Development (USAID), which gathered the information as part of a registration process (Voluntary Foreign Aid Programs, 1988-94). The USAID registry reports the amounts of private donations and government funding received by each organization in each year. The registry also contains other useful data such as the amounts of private and public in-kind support (e.g., freight, food), grants from private foundations, and amounts spent on fund-raising and administration.

The roster of organizations in the USAID registry was relatively stable across years; however, there were a few changes (mostly new registrations of existing organizations). To reduce the amount of missing data, we supplemented the USAID information by obtaining annual financial statements directly from 28 organizations that registered after 1986. We also obtained financial statements for another large organization, the U.S. Committee for United Nations International Children's Emergency Fund (UNICEF), that never registered. ${ }^{12}$ After the registry and supple-

\footnotetext{
${ }^{11}$ Payne examined contributions to domestic social service organizations and used transfer payments to individuals and other organizations as instruments for government support. The difficulty with these instruments is that they might directly affect contributions by reducing need among the organizations' potential beneficiaries. Khanna and Sandler examined charitable organizations in the United Kingdom and used as instruments annual measures of the government's total grant making and deficit spending. Their aggregate measures might alter contributions through effects on recipients' need or donors' incomes.

${ }^{12}$ U.S. support for UNICEF was provided each year as a separate line item in the Foreign Assistance Act rather than through the USAID; the analysis includes this line item funding as a source of public support. Where possible, the study also independently obtained financial statements from the organizations in the USAID registry and verified the USAID figures.
} 
mental data were input, we removed organizations that (i) were still missing data in any year, (ii) reported zero contributions in any year, or (iii) directed more than one-quarter of their program expenditures toward the United States. In addition, we dropped observations for another organization, the United Israel Appeal, after specification tests indicated that it was an outlier. The first two screens eliminate some small forming and declining organizations. The third screen orients the data set toward contributions that are driven by altruism or joy of giving rather than personal consumption or insurance motives; unfortunately, it removes some large organizations that are commonly identified with international relief including the American Red Cross, Church World Service, Feed the Children, Habitat for Humanity, and Project Hope.

Despite these exclusions, the resulting data still provide a reasonably complete description of U.S. giving to international relief and development. The included organizations account for just over three-quarters of the total annual public support and just over half of the private contributions recorded by all organizations in the USAID registry. The monetary portion of the private contributions is about two-thirds of the amount of total overseas contributions computed independently by Kaplan (1993) from data from the Internal Revenue Service. Appendix table B1 lists the 125 organizations in our data set along with their average annual level of private contributions.

At first glance, 1986-92 might not look like a good period in which to examine the effects of public overseas relief expenditures because there was little variation over this span in the total levels of U.S. bilateral development and food assistance. However, the trends in total assistance levels mask important compositional shifts that are captured in the study's data set. Over this period, the United States increased the percentage of foreign aid that it channeled through private agencies. ${ }^{13}$ Accordingly, U.S. public monetary and in-kind support of organizations in the analysis data set rose from just under $\$ 1$ billion in 1987 to $\$ 1.4$ billion in 1992. Funding for population planning and general health programs fell dramatically, and assistance targeted toward child survival and treatment and prevention of AIDS rose. There were also shifts in geographic emphasis such as the commencement of the Development Fund for Africa in fiscal year 1988. Democratization in the Philippines, the end of the conflict in Central America, and the end of the Cold War resulted in several other area-specific development initiatives. Finally, there were modest increases in funding received from other gov-

\footnotetext{
${ }^{13}$ Amendments to the Foreign Assistance Act for fiscal years 1982 and 1983 required that at least 12 percent, and encouraged that at least 16 percent, of the funding for agricultural development, health and population programs, education, energy development, disaster assistance, and development assistance for sub-Saharan Africa be provided through voluntary organizations. The requirement was raised to 13.5 percent in 1986 .
} 
ernments and international institutions such as the World Bank, which are included in the study's measures of public support.

Besides the annual contributions and public support information, the analysis data also include measures of fund-raising and administrative expenses. The study combines these data with total expenditure data to calculate efficiency prices in a manner that is now standard in empirical studies (see, e.g., Khanna et al. 1995); specifically, the price is defined as the reciprocal of the share of service expenditures (total expenditures less fund-raising and administrative expenses) in total expenditures. It should be noted that there is some dispute regarding whether efficiency prices belong in the model ${ }^{14}$ The study includes price measures for comparability with previous studies; however, the crowdout estimates are not sensitive to their inclusion or omission.

Data from a separate set of USAID executive contact lists (U.S. Agency for International Development 1988, 1991, 1992) were used to determine the activities in which the charities were engaged and the regions of the world in which they operated. The contact lists identified 49 service activities and seven regions. These data provide the dimensions by which the study defines the extent of program overlap across organizations. ${ }^{15}$ Following the notation from the previous section, let $Q_{j, t}$ denote total expenditures by all organizations in year $t$ on the specific mix of services supported by organization $j$. The service mix can be thought of as a unique activity, and expenditures to this activity can be written as a weighted sum of expenditures by related organizations:

$$
Q_{j, t}=\sum_{k=1}^{J} w_{j, k} \lambda_{k, t} \tilde{H}_{k, t}
$$

where $0 \leq w_{j, k} \leq 1$ and $w_{j, j}=1$ for $j, k=1, J$ (the weights represent the share of $k$ 's expenditures dedicated to $j$ 's service mix). Related service expenditures by organizations other than $j$ can then be defined as

$$
Q_{-j, t}=Q_{j, t}-\lambda_{j, t} \tilde{H}_{j, t}=\sum_{k \neq j} w_{j, k} \lambda_{k, t} \tilde{H}_{k, t}
$$

\footnotetext{
${ }^{14}$ For instance, Steinberg (1986) has argued that a rational donor might view fundraising and administration as fixed costs, consider his or her full contribution as augmenting program services, and therefore not be influenced by expenditures on these activities. Similarly, a donor who is entirely motivated by joy of giving would be indifferent to the amount spent on fund-raising and administration. Altruists might actually benefit from fund-raising if it increases the contributions of others and the marginal return to fund-raising exceeds one. Beyond these conceptual issues, there is an empirical problem that identification of the price effect rests on functional form assumptions regarding the direct effects of fund-raising and administration.

${ }^{15}$ We also gathered data on regions and activities from other sources (e.g., the organizations' annual reports). The other regional indicators are combined with those from the executive contact list to create the regional dummies. The results are not sensitive to the use of the other activity indicators to define program overlap.
} 
TABLE 1

Variable Means, 1987-92

\begin{tabular}{lcc}
\hline \hline Variable & Mean & $\begin{array}{c}\text { Standard } \\
\text { Deviation }\end{array}$ \\
\hline Total private contributions* & 13.203 & 27.449 \\
Fund-raising expenditures* & 1.093 & 3.257 \\
Administrative expenditures* & 1.558 & 2.737 \\
Efficiency price & 1.235 & .399 \\
Direct government support* & 9.723 & 32.810 \\
Activities of organizations: & .672 & .470 \\
Preventative health & .464 & .499 \\
Other medical assistance & .072 & .259 \\
Agricultural assistance & .424 & .495 \\
Rural development & .400 & .490 \\
Small enterprise development & .672 & .470 \\
Other development activities & .680 & .467 \\
Education & .536 & .499 \\
Emergency assistance & .240 & .427 \\
Political assistance & .264 & .441 \\
Family planning & .048 & .214 \\
Housing assistance & & \\
Geographic areas served: & .736 & .441 \\
Africa & .672 & .470 \\
Asia & .456 & .498 \\
Eastern Europe & .776 & .417 \\
Central and South America & .176 & .381 \\
Israel & .264 & .441 \\
Near East (other than Israel) & .152 & .359 \\
Significant activity in United States & & \\
\hline Note.-There are 750 annual organization observations (125 organizations). & \\
* Amount in millions of constant 1992 dollars. & &
\end{tabular}

The study's data set contains the total service expenditures for each organization, $\lambda_{j, r} \tilde{H}_{j, t}$, but not the expenditure shares, $w_{j, k}$. Consequently, the study approximates $Q_{-j, t}$ using the ratio of the number of services common to $j$ and $k$ and the total number of services offered by $k$ as an approximation for $w_{j, k}$ and letting $\hat{Q}_{-j, t}=\sum_{k \neq j} \hat{w}_{j, k} \lambda_{k, t} \tilde{H}_{k, t}$. The empirical analysis considers alternative specifications of $\hat{Q}_{-j, t}$ based (i) on the activity categories alone and (ii) more narrowly on the intersection of activities and regions.

The data on regions and activities are also employed as independent controls in the empirical analysis. Because of concerns regarding multicollinearity, the 49 activity categories used to form $\hat{Q}_{-j, t}$ are collapsed to a smaller set of 11 activities. Reasonable assumptions and a series of exploratory factor analyses guided the selection of condensed categories. The regions and collapsed set of 11 activity categories are listed in table 1.

The study also uses data from the executive contact lists and the Encyclopedia of Associations (Gale Research Co., 1985-90) to identify changes in the leadership of the organizations. The organizations in 
the data set experienced 147 changes in leadership (just over one per organization).

Means and standard deviations for the private contributions and other analysis variables are reported in table 1 . All dollar amounts in the data set are adjusted to 1992 levels using the implicit gross domestic product deflator. Because the subsequent empirical analysis includes lagged realizations of some variables, the effective length of the panel is reduced from seven to six years (1987-92). As the figures in the table reveal, the organizations in the data set are very large: the average annual level of private contributions to each organization is $\$ 13$ million. The figures also indicate that the organizations receive a great deal of government funding, nearly $\$ 10$ million per organization per year.

\section{Econometric Analysis}

The study estimates regressions of the determinants of private contributions to organization $j$ in year $t$. Each of the regressions is specified as

$$
H_{j, t}=\gamma_{G} H_{G, j, t}+\gamma_{Q} \hat{Q}_{-j, t}+\mathbf{X}_{j t}^{\prime} \boldsymbol{\Gamma}+\epsilon_{j, t}
$$

where $H_{G, j, t}$ denotes direct government support, $\hat{Q}_{-j, t}$ denotes related service expenditures by other organizations, $\mathbf{X}_{j, t}$ is a vector of other observed time-varying determinants (the organization's own efficiency price, its current and lagged fund-raising expenditures, and the current effective price of related charitable activities), and $\epsilon_{j, t}$ is an unobserved organization- and year-specific error term. The parameters to be estimated are the coefficients on government support and other organizations' spending, $\gamma_{G}$ and $\gamma_{Q}$, and the general vector of coefficients, $\boldsymbol{\Gamma}$. Because of the enormous variation in the sizes of the organizations, heteroskedasticity is likely to be a problem. Accordingly, the coefficient standard errors for all the regressions are computed using White's (1980) heteroskedasticity-consistent method.

The principal regression results are reported in table 2. From left to right, the specifications in table 2 include additional sets of dummy variable controls to reduce possible biases associated with different types of omitted variables. Column $a$ lists estimates from a regression that includes dummy variables for each year. The year dummies account for period-specific factors such as domestic changes in economic conditions, tax laws, and expenditure policies and global changes in need that might affect donors to all organizations. The regression in column $b$ adds dummy variables for each organization. These dummies control for organization-specific characteristics such as program mix, managerial ability, religious orientation, and institution ideology that might affect 
TABLE 2

Regression Analysis of Private Contributions to International Relief and DEVELOPMENT

\begin{tabular}{|c|c|c|c|c|c|}
\hline \multirow[b]{2}{*}{ VARIABLE } & \multicolumn{5}{|c|}{ SPECIFICATION } \\
\hline & $(a)$ & $(b)$ & $(c)$ & $(d)$ & $(e)$ \\
\hline $\begin{array}{l}\text { Government funding } \\
\quad\left(H_{G, j, t}\right)\end{array}$ & $\begin{array}{r}-.022 \\
(.032)\end{array}$ & $\begin{array}{r}-.064 \\
(.064)\end{array}$ & $\begin{array}{r}-.088 \\
(.060)\end{array}$ & $\begin{array}{r}-.093 \\
(.059)\end{array}$ & $\begin{array}{l}-.129 * * \\
(.054)\end{array}$ \\
\hline $\begin{array}{l}\text { Other organizations' ser- } \\
\text { vice expenditures }\left(\hat{Q}_{-i, j}\right)\end{array}$ & $\begin{array}{l}.0015 \\
(.0012)\end{array}$ & $\begin{array}{l}-.019 * * * \\
(.006)\end{array}$ & $\begin{array}{l}-.041 * * * \\
(.010)\end{array}$ & $\begin{array}{l}-.044 * * * \\
(.010)\end{array}$ & $\begin{array}{l}-.054 * * * \\
(.013)\end{array}$ \\
\hline Own efficiency price $\left(P_{H, j, t}\right)$ & $\begin{array}{l}-3.395 \\
(2.814)\end{array}$ & $\begin{array}{c}.499 \\
(.333)\end{array}$ & $\begin{array}{l}.343 \\
(.368)\end{array}$ & $\begin{array}{l}.236 \\
(.384)\end{array}$ & $\begin{array}{l}1.518 * * * \\
(.474)\end{array}$ \\
\hline $\begin{array}{l}\text { Effective price of alterna- } \\
\text { tive charitable activities } \\
\quad\left(\pi_{R, j, t}\right)\end{array}$ & $\begin{array}{l}12.688 * * * \\
(3.655)\end{array}$ & $\begin{array}{l}6.007 * * \\
(2.711)\end{array}$ & $\begin{array}{l}5.629 * * \\
(2.725)\end{array}$ & $\begin{array}{l}5.715^{* *} \\
(2.691)\end{array}$ & $\begin{array}{l}17.439 * * * \\
(3.728)\end{array}$ \\
\hline $\begin{array}{l}\text { Fund-raising expenditures } \\
\text { in current year }\end{array}$ & $\begin{array}{l}5.496 * * * \\
(1.605)\end{array}$ & $\begin{array}{l}6.856 * * * \\
(1.382)\end{array}$ & $\begin{array}{l}6.546 * * * \\
(1.290)\end{array}$ & $\begin{array}{l}6.453 * * * \\
(1.258)\end{array}$ & $\begin{array}{l}6.060 * * * \\
(1.250)\end{array}$ \\
\hline $\begin{array}{l}\text { Fund-raising expenditures } \\
\text { lagged }\end{array}$ & $\begin{array}{c}1.562 \\
(1.638)\end{array}$ & $\begin{array}{l}2.392^{* * *} \\
(.966)\end{array}$ & $\begin{array}{l}2.437 * * * \\
(.778)\end{array}$ & $\begin{array}{l}2.500 * * * \\
(.763)\end{array}$ & $\begin{array}{l}2.349 * * \\
(.931)\end{array}$ \\
\hline Year effects (5) & yes & yes & yes & yes & yes \\
\hline Organization effects (124) & no & yes & yes & yes & yes \\
\hline Activity $\times$ year effects $(55)$ & no & no & yes & yes & yes \\
\hline $\begin{array}{l}\text { Geographic area } \times \text { year ef- } \\
\text { fects }(35)\end{array}$ & no & no & no & yes & yes \\
\hline $\begin{array}{l}\text { Organization leadership ef- } \\
\text { fects }(147) \\
R^{2}\end{array}$ & $\begin{array}{c}\text { no } \\
.685\end{array}$ & $\begin{array}{r}\text { no } \\
.972\end{array}$ & $\begin{array}{r}\text { no } \\
.976\end{array}$ & $\begin{array}{r}\text { no } \\
.977\end{array}$ & $\begin{array}{r}\text { yes } \\
.984\end{array}$ \\
\hline
\end{tabular}

the pool of donors (see Rose-Ackerman 1982, 1986); these effects may also control for correlation in the unobserved determinants of contributions across organizations (Case 1991).

The regressions in the next two columns add interacted controls. Specification $c$ adds interactions of the activity dummies from table 1 with the full set of year dummies; specification $d$ includes interactions of the regional dummies with the year dummies. The activity $\times$ year and geographic area $\times$ year variables pick up changes in particular groups' needs for assistance, the emergence of new targeted government initiatives and other shifts in program emphasis by the USAID, and unobserved contributions from outside the United States to the same activities and regions.

The regression in column $e$ of table 2 replaces the fixed organization dummies with a more comprehensive set of dummy variables that are specific to administrations (changes in the president or chief executive officer) within each organization. Changes in administration might coincide with the initiation of fund-raising campaigns, changes in program 
emphasis, and other activities that jointly affect contributions, government support, and the other explanatory variables.

Specification tests indicate that the year, organization, and activity $\times$ year dummy variables are all jointly significant and that specifications $a$ and $b$ can be rejected. However, once these other controls are included, adding the geographic area $\times$ year and leadership change variables does not significantly increase the model's explanatory power. Although we are not completely justified on statistical grounds, we prefer to base our examination of complete crowd-out on model $e$ because it utilizes the most extensive set of controls for unobserved heterogeneity and generates the largest crowd-out point estimates. For brevity, the bulk of our discussion focuses on the estimation results from this model.

The coefficient estimates for government spending and service expenditures from specification $e$ strongly reject hypotheses of complete crowd-out and thus indicate that donors' preferences are not guided at the margin by altruism. The point estimates for both coefficients are small and statistically different from -1 . Lower bounds for 95 percent confidence intervals around $\hat{\gamma}_{G}$ and $\hat{\gamma}_{Q}$ are consistent with crowd-out of at most 23 cents per dollar of government spending and 8 cents per dollar of other organizations' spending. When we compare results across specifications, the coefficients on government and other organizations' spending are moderately sensitive to the inclusion of additional sets of controls, with specification $e$ yielding the strongest crowd-out results. While this lends some credence to the statistical criticisms of previous econometric work, the literature's chief finding of small crowd-out effects is nevertheless upheld.

Among the other results from specification $e$, the coefficients on contemporaneous and lagged fund-raising expenditures are significantly positive. The estimates indicate that these expenditures are cost-effective, on average returning over $\$ 8$ in contributions (over two years) for each dollar spent. The coefficient on $P_{H}$ is significantly positive, a result that runs counter to the interpretation of this variable as a price measure. The coefficient on the cross-price term is also significantly positive. When we look across regressions, the results for the price and fundraising variables are sensitive to the inclusion of the organization effects; the price variables are also sensitive to the inclusion of the leadership change effects.

Additional sensitivity analyses.-Table 3 lists results from respecifications of model $e$ that replace the contemporaneous measures of government support, other organizations' expenditures, and prices with one-year lags of these variables (specification $f$ ); use a narrower description of program overlap based on both activity and region (specification $g$ ); and combine the narrower overlap description with one-year lags (specification $h$ ). The respecified models are estimated to check the robust- 
TABLE 3

Regression Analysis of Private Contributions to International Relief and Development: Specifications Incorporating Lags and Alternative Definitions FOR RELATED ORganizATIONS

\begin{tabular}{|c|c|c|c|}
\hline \multirow[b]{2}{*}{ VARIABLE } & \multicolumn{3}{|c|}{ SPECIFICATION } \\
\hline & $(f)$ & $(g)$ & (h) \\
\hline Government funding $\left(H_{G, j, t}\right)$ & $\cdots$ & $\begin{array}{l}-.120 * * \\
(.053)\end{array}$ & $\ldots$ \\
\hline $\begin{array}{l}\text { Government funding lagged } \\
\left(H_{G, j, t-1}\right)\end{array}$ & $\begin{array}{l}.041 \\
(.070)\end{array}$ & $\ldots$ & $\begin{array}{l}.039 \\
(.068)\end{array}$ \\
\hline $\begin{array}{l}\text { Other organizations' service ex- } \\
\text { penditures }\left(\hat{Q}_{-j . t}\right)\end{array}$ & $\ldots$ & $\begin{array}{l}-.055^{* * *} \\
(.014)\end{array}$ & $\ldots$ \\
\hline $\begin{array}{l}\text { Other organizations' service ex- } \\
\text { penditures lagged }\left(Q_{-j, t-1}\right)\end{array}$ & $\begin{array}{l}-.053 * * * \\
(.016)\end{array}$ & $\ldots$ & $\begin{array}{l}-.077 * * * \\
(.023)\end{array}$ \\
\hline Own efficiency price $\left(P_{H, j, t}\right)$ & $\ldots$ & $\begin{array}{l}1.441 * * * \\
(.546)\end{array}$ & $\ldots$ \\
\hline $\begin{array}{l}\text { Own efficiency price lagged } \\
\left(P_{H, j, t-1}\right)\end{array}$ & $\begin{array}{l}-.196 \\
(.544)\end{array}$ & $\ldots$ & $\begin{array}{l}-.313 \\
(.523)\end{array}$ \\
\hline $\begin{array}{l}\text { Effective price of alternative chari- } \\
\text { table activities }\left(\pi_{R, j, t-1}\right)\end{array}$ & $\ldots$ & $\begin{array}{l}29.570 * * * \\
(7.621)\end{array}$ & $\ldots$ \\
\hline $\begin{array}{l}\text { Effective price of alternative chari- } \\
\text { table activities lagged }\left(\pi_{R, j, t-1}\right)\end{array}$ & $\begin{array}{c}3.867 \\
(2.888)\end{array}$ & $\ldots$ & $\begin{array}{c}5.164 \\
(5.513)\end{array}$ \\
\hline $\begin{array}{l}\text { Fund-raising expenditures in cur- } \\
\text { rent year }\end{array}$ & $\begin{array}{l}5.003 * * * \\
(1.339)\end{array}$ & $\begin{array}{l}6.170 * * * \\
(1.219)\end{array}$ & $\begin{array}{l}5.161 * * * \\
(1.334)\end{array}$ \\
\hline Fund-raising expenditures lagged & $\begin{array}{l}2.637 * * * \\
(.995)\end{array}$ & $\begin{array}{l}2.523 * * * \\
(.939)\end{array}$ & $\begin{array}{l}2.673 * * * \\
(1.017)\end{array}$ \\
\hline $\begin{array}{l}\text { Expenditure shares for } \hat{Q}_{-j, t} \text { de- } \\
\text { fined in terms of }\end{array}$ & activities & $\begin{array}{l}\text { activities } \times \\
\text { geographic } \\
\text { areas }\end{array}$ & $\begin{array}{l}\text { activities } \times \\
\text { geographic } \\
\text { areas }\end{array}$ \\
\hline$R^{2}$ & .983 & .984 & .983 \\
\hline
\end{tabular}

NoTE.-All results are based on 750 observations (six years of data for 125 organizations). Dependent and righthand-side funding/expenditure variables are expressed in millions of constant 1992 dollars. All specifications are estimated using ordinary least squares and include year, organization, activity $\times$ year, geographic area $\times$ year, and organization leadership fixed effects. Heteroskedasticity-consistent standard errors (White 1980) appear in parentheses.

** Significant at the .05 level.

*** Significant at the .01 level.

ness of our results to several potential concerns. First, there is a possibility of bias if the explanatory variables in the previous models are contemporaneously correlated with the unobserved determinants of contributions, that is, if some residual correlation exists after the different fixed-effect controls are applied. The use of lagged variables might eliminate this problem. Second, the lagged measures may provide better descriptions than the contemporaneous measures of the information available to donors when they make their contribution decisions. Third, the interaction of activities and regions may also better describe donors' views of the overlap between organizations.

The results from table 3 again reject the hypothesis of complete crowdout. For model $f$, the coefficient on spending by other organizations remains small but statistically significant, whereas the coefficient on government spending changes sign and loses its significance. The co- 
efficients on the lagged price variables are also small and insignificant. Specification $g$, which uses contemporaneous measures but a narrower definition of program overlap, generates crowd-out estimates that are nearly identical to those from table 2 . When lags are introduced in specification $h$, the evidence regarding crowd-out again becomes weaker.

Other respecifications of model $e$ have been estimated to check the sensitivity of the crowd-out results to the inclusion of the price and fundraising variables and the omission of controls for administrative expenditures. The estimates indicate that the study's findings are robust to these other specification issues. For brevity, detailed results from these regressions are not reported. ${ }^{16}$

While the robustness of the estimation results to the inclusion of so many different types of controls increases our confidence regarding our rejection of complete crowd-out, the sensitivity analyses are not definitive. Instrumental variable methods might have provided more convincing estimates of the effect of government support on private contributions; unfortunately, we could not locate any theoretically justified instruments that were reliable predictors of government spending. ${ }^{17}$ Because the regressions from tables 2 and 3 do not control for every possible common factor influencing private and government support, we must consider whether the remaining unobserved sources of covariation are large enough to overturn our findings.

Beyond the determinants specified in our theoretical model, we have already conjectured that the main additional influences on private and government support are changes in the needs of recipients (such as those caused by epidemics, natural disasters, and war) and in the focus and reputation of an organization's officers, staff, and operations. The activity and area effects interacted with year dummies in our models capture some, but not all, of the changes in need. To illustrate, consider responses to a health crisis such as the AIDS epidemic. If the crisis occurs throughout the world, then the medical assistance activity $\times$ year effect controls for the common effect of the crisis on private and government support. The activity $\times$ year controls are also efficacious if the crisis is localized (e.g., in Africa) and private donors and the government respond simply to the type, rather than location, of the crisis. If these conditions are not met, then additional controls might be needed for the separate effects of crises within regions.

Similarly, the administration-specific dummies control for changes in each organization's reputation, direction, and leadership when there is a change in top executives. However, the dummies fail to control for

\footnotetext{
${ }^{16}$ The results are available from the authors in an unpublished appendix.

${ }^{17}$ Besides addressing biases from omitted variables, instrumental variables methods would also address possible biases associated with the simultaneous determination of private and government support.
} 
changes in these characteristics over the course of an administration. For example, within an administration there may be surges in grant writing and development efforts that lead to simultaneous bursts in public and private support.

It is important to realize, however, that there are numerous sources of independent variation in the government support variable. For instance, government support may be influenced by the strategic and political importance of countries in which aid is directed, by domestic political considerations favoring specific activities or organizations, and by the availability of excess supplies and services (supplemental food, ocean freight, etc.). Also, compared to private donors, the government may be more or less willing to fund long-term projects, riskier projects, and innovative projects. An adverse side effect of our dummy controls for time, activity, area, and leadership effects is that they absorb some of this independent variation along with the confounding variation from omitted variables.

As the foregoing discussion indicates, the list of controls is not exhaustive, and the resulting estimates may still be biased. Nevertheless, the controls are quite extensive and go far beyond what previous studies have been able to include. In the end, the interpretation of the estimates comes down to a judgment about the balance of the independent and confounding sources of variation in the government support measure after the controls have been applied.

An alternative interpretation of the rejection of complete crowd-out is that although donors' altruism is effective at the margin, their lack of knowledge about government funding of international relief organizations offsets the larger crowd-out that would otherwise appear in the data. Although the ability of our data to examine this possibility is limited, we did construct a proxy for donor uncertainty over government funding for each organization in a given year by using the variance of funding over the previous three years. Including this proxy as a regressor in several respecifications of model $e$ led to only minor changes in the crowd-out estimates. In addition, rudimentary calculations indicate that a very large amount of uncertainty is necessary to make complete crowdout deceptively look like zero crowd-out. It is not known whether the degree of uncertainty that actually exists is this large; if it is, however, other calculations indicate that donors would be willing to pay very large amounts to have such uncertainty eliminated. ${ }^{18}$ Again, although

\footnotetext{
${ }^{18}$ For simplicity, these calculations are based on donor preferences that are purely altruistic with a minimum demand for own consumption $\left(\zeta_{\min }\right)$ :

$$
U=(1-\eta) \ln \left(y_{i}-h_{i}-\tau_{i}-\zeta_{\min }\right)+\eta \ln \left(h_{i}+H_{G}\right)
$$

thus a threshold level of own consumption is first met before donations are made. When these preferences are parameterized with an altruism coefficient $\eta=0.10$ and minimal consumption $\zeta_{\min }=40,000$, an income $y_{i}$ of $\$ 50,000$ leads to an optimal contribution
} 
there are no data on the actual amounts donors would have to pay to remove this uncertainty, it seems unlikely that these costs are prohibitive because information on government support can be obtained directly from the charity with little monetary or time expense once donors have received a mail solicitation.

Turning attention toward the evidence for zero crowd-out, we find it to be somewhat mixed but on balance consistent with joy-of-giving motives. Government crowd-out is significantly different from zero only in specification $e$, but this specification can be rejected in favor of $c$. While crowd-out from other charities' expenditures is significant in specification $c$, it is so small that it could easily be explained by other phenomena, such as the presence of some inframarginal changes in the expenditure data. Likewise, the small changes in both crowd-out estimates when the activity $\times$ year effects are added suggest a minor role of needs.

\section{Conclusion}

This paper conducts a theoretical and empirical investigation of the altruistic and joy-of-giving motivations underlying contributions to charitable activities. Our theoretical analysis examines the asymptotic crowdout properties of an impurely altruistic model of giving. Previous theoretical studies of this model have found that changes in government support for a charitable activity incompletely crowd out private contributions. In contrast, our analysis shows that in an economy with an infinitely large number of donors, impurely altruistic preferences lead to either asymptotically zero or asymptotically complete crowd-out. Asymptotically zero crowd-out occurs when joy-of-giving motives remain effective among the population but large expenditures on the charitable activity depress the marginal utility associated with altruism. If, however, altruistic motives remain marginally effective, crowd-out is asymptotically complete. Because there are many standard utility functions that satisfy the former condition, asymptotically zero crowd-out appears to be a likely outcome. The difference in the model's small and large sample predictions offers a potential reconciliation of differences in previous experimental and econometric findings.

$h_{i}^{*}=\$ 1,000$ (2 percent of income) when $H_{G}=0$. Under donor certainty, a change in the government contribution to $H_{G}=\$ 100$ financed by an equivalent lump-sum tax would crowd out $\$ 100$ of the private contribution. If, instead, the donor considers $H_{G}$ to be a random variable with $E\left[H_{G}\right]=\$ 100$, an accompanying standard deviation of greater than three times this amount $(\$ 369)$ is necessary to produce zero crowd-out (the optimal $h_{i}$ under uncertainty is calculated using a second-order Taylor expansion of $\left.E\left[\left(h_{i}+H_{G}\right)^{-1}\right]\right)$. Moreover, because donor utility is lower under uncertainty, the donor in this example would be willing to pay up to $\$ 71$ to have the uncertainty removed. This is a large amount relative to the change in the government's contribution from zero to $\$ 100$. 
For our empirical analysis we assemble a 1986-92 panel of contribution and expenditure data for 125 international relief and development organizations. The data are new and permit us to interpret crowdout estimates as tests for altruism. The estimation methodology-which controls for unobserved institution-specific factors, year-to-year changes in need, changes in organization leadership, and interorganization crowd-out between institutions that provide similar services and operate in the same regions of the world-addresses several statistical problems that potentially affected previous empirical studies of crowd-out. The model generates estimates of both government and interorganization crowd-out that are very small. The findings of small crowd-out effects are robust to alternative definitions of the degree of similarity across organizations and the use of lagged measures of government funding and related organizations' service expenditures. While there are some qualifications concerning data representativeness and the potentially confounding role of donor uncertainty, we argue that these problems are likely to have only minor consequences. More important, a potential bias remains in the results because of the endogeneity of government support. The amount of unobserved common variation between government support and private donations-relative to the amount of independent variation in government support-that survives the array of fixed effects we use determines the size of the bias.

Although these qualifications must be kept in mind during any interpretation of the empirical findings, the results as they stand suggest that altruistic motivations behind contributions to international relief and development are extremely weak at the margin. This interpretation is compatible with the theoretical finding that even a small amount of marginally effective altruism would have led to asymptotically complete crowd-out. This interpretation does not necessarily imply that altruistic concern is absent from the donors' utility functions, only that it is not effective for the size of the population and level of contributions we observe. While the theoretical analysis demonstrates that the impurely altruistic model reconciles these results with previous experimental evidence, the empirical analysis does not directly test this proposition. In future research, we hope to consider the relationship between the number of donors and crowd-out using both experimental and secondary data.

Likewise, the empirical analysis suggests that modest changes in U.S. development assistance do not lead to comparably sized adjustments in private contributions to international poverty relief. At the same time, however, the theoretical analysis shows that it is not possible to extrapolate beyond this interpretation to consider larger changes in government support. If one accepts the conjecture that the preferences motivating these contributions are similar to those underlying domestic 
poverty relief, parallel conclusions could be drawn concerning the relationship between changes in public welfare spending and private assistance to the domestic poor.

\section{Appendix A}

\section{Proofs of Theoretical Results}

Proof of Proposition 1

(i) If $\lim _{N \rightarrow \infty} A_{N}=0$, then $\lim _{N \rightarrow \infty} \kappa_{N}=0$. (ii) If $\lim _{N \rightarrow \infty} A_{N}=\infty$, then $\lim _{N \rightarrow \infty} \kappa_{N}=$ -1. (iii) If $\lim _{N \rightarrow \infty} A_{N}=A>0$, then $\lim _{N \rightarrow \infty} \kappa_{N}=-A /(1+A)$, where $A$ is finite. Q.E.D.

Proof of Corollary 1.1

If $q_{1}+q_{2}-1=O\left(N^{\phi}\right)$, then $A_{N}=O\left(N^{\phi+1}\right)$. Thus (i) $\phi<-1$ implies $\phi+1<0$ and $\lim _{N \rightarrow \infty} A_{N}=0$, (ii) $\phi>-1$ implies $\phi+1>0$ and $\lim _{N \rightarrow \infty} A_{N}=\infty$, and (iii) $\phi=-1$ implies $\phi+1=0$ and $\lim _{N \rightarrow \infty} A_{N}=A>0$. Q.E.D.

Proof of Corollary 1.2

In the representative donor model (when $d y_{i}=0$ )

$$
d H=\frac{-\frac{q_{1}}{q_{1}+q_{2}} N d \tau-N \frac{1-\left(q_{1}+q_{2}\right)}{q_{1}+q_{2}} d H_{G}}{1+N \frac{1-\left(q_{1}+q_{2}\right)}{q_{1}+q_{2}}},
$$

where $N d \tau=d H_{G}$ can be factored out. The income effect due to taxes is then $-q_{1}\left(q_{1}+q_{2}\right)^{-1} /\left(1+A_{N}\right)$. The limit of this term is $-\lim _{N \rightarrow \infty} q_{1}$ in case $\mathrm{i}$, is zero in case ii, and is $\left(-\lim _{N \rightarrow \infty} q_{1}\right) /(1+A)$ in case iii. The respective necessary modifications to the crowd-out effects immediately follow. Q.E.D.

Proof of Proposition 2

Assumption 1. For all levels of the public good $\tilde{H}, U_{c c}, U_{h c}$, and $U_{h h}$ are finite and $U_{c c}-2 U_{h c}+U_{h h}$ is bounded away from zero.

LEMMA 1. Under assumption 1, if $U_{H H}, U_{H b}$, and $U_{H c}$ converge to zero, then $q_{1}+q_{2}-1$ converges to zero. Also, its rate of convergence is the same as for $U_{H H}+U_{H h}-U_{H c}$

Proof. Take the differentials of the first-order condition (5) with respect to $Z_{i}$ and $H_{-i}+H_{G}$ and then solve for $\partial \tilde{H}^{*} / \partial Z_{i}$ and $\partial \tilde{H}^{*} / \partial\left(H_{-i}+H_{G}\right)$ in terms of the second partials of $U$. Recall from (6) that these expressions are $q_{1}$ and $q_{2}$, respectively. Adding them together yields

$$
q_{1}+q_{2}=\left(1+\frac{U_{H H}+U_{H h}-U_{H c}}{U_{c c}-2 U_{h c}+U_{h h}+U_{H h}-U_{H c}}\right)^{-1} .
$$

Under assumption 1, the lemma follows immediately. Because we shall subsequently show that both $U_{H h}$ and $U_{H c}$ converge to zero, the technical problem of 
evaluating the limit when $U_{c c}-2 U_{h c}+U_{h h}=-\left(U_{H h}-U_{H c}\right)$ is avoided by the assumption that $U_{c c}-2 U_{h c}+U_{h h}$ is bounded away from zero. Q.E.D.

Assumption 2a. $U\left(c_{i}, \tilde{H}, h_{i}\right)$ is (i) concave and (ii) twice continuously differentiable.

Assumption 2b. (i) $U_{H}>0$, (ii) $U_{c}>0$, and (iii) $U_{h}>0$ for all $\tilde{H}$ (nonsatiation).

Assumption 2c. $U_{H}\left(c_{i}, h_{i}, h_{i}\right)<\infty$ for $h_{i}>0$.

LEмma 2. If the joy-of-giving motive is strictly operative for all levels of the public good and utility is nonsatiable in the public good and continuously differentiable, then $h_{i}^{*}(N)$ is bounded away from zero as $N \rightarrow \infty$.

Proof. We wish to establish that $\lim _{N \rightarrow \infty} h_{i}^{*}(N) \geq \underline{h}>0$ by assuming that $\lim _{N \rightarrow \infty} h_{i}^{*}(N)=0$ and then showing that this contradicts continuity of the utility function's first derivatives. Without loss of generality, the proof neglects the government provision $H_{G}$.

First, note that, given $H_{-i}(N), h_{i}^{*}(N)$ solves

$$
U_{h}\left(x_{i}-h_{i}^{*}(N), H_{-i}(N)+h_{i}^{*}(N), h_{i}^{*}(N)\right)+U_{H}(\cdot, \cdot, \cdot)=U_{c}(\cdot, \cdot, \cdot),
$$

which, under the assumption that $U_{H}>0$, implies

$$
U_{h}\left(x_{i}-h_{i}^{*}(N), H_{-i}(N)+h_{i}^{*}(N), h_{i}^{*}(N)\right)<U_{c}(\cdot, \cdot, \cdot) .
$$

Define $h_{i}^{J}(N)$ as the contribution that would equate $U_{h}(\cdot, \cdot, \cdot)=U_{c}(\cdot, \cdot, \cdot)$. Clearly, $h_{i}^{J}(N)<h_{i}^{*}(N)$. An operative joy-of-giving motive (strictly operative is not necessary at this point) implies $h_{i}^{J}(N)>0$.

Now assume $\lim _{N \rightarrow \infty} h_{i}^{*}(N)=0$. Because $0<h_{i}^{J}(N)<h_{i}^{*}(N)$, this must imply $\lim _{N \rightarrow \infty} h_{i}^{J}(N)=0$. However, this violates the continuity of $U_{h}$ and $U_{c}$. To see this, define a function

$$
f\left(h_{i}(N)\right) \equiv U_{h}\left(x_{i}-h_{i}(N), H_{-i}(N)+h_{i}(N), h_{i}(N)\right)-U_{c}(\cdot, \cdot, \cdot) ;
$$

hence, $f(\cdot)$ is continuous. By construction, $f\left(h_{i}^{J}(N)\right)=0$. Thus the continuity of $f(\cdot)$ requires that $\lim _{h l(N) \rightarrow 0} f\left(h_{i}^{J}(N)\right)=0$. But if the joy of giving is strictly operative at all $H$, then regardless of whether $H_{-i}(N)$ is converging or diverging, we must have $f(0) \geq \Delta>0$. This establishes the contradiction. Q.E.D.

Remarks for lemma 2.-The more formal continuity argument follows. Recall that $f(\cdot)$ is continuous at zero if, for every $\epsilon>0$, there is a $\delta>0$ such that, for all $h_{i}^{J}(N)$ satisfying $\left|h_{i}^{J}(N)-0\right|<\delta,\left|f\left(h_{i}^{J}(N)\right)-f(0)\right|<\epsilon$. Now pick $\epsilon=\Delta / 2$. For all $\delta>0$ and all $h_{i}^{J}(N)$ satisfying $\left|h_{i}^{J}(N)-0\right|<\delta$, we have $\left|f\left(h_{i}^{J}(N)\right)-f(0)\right|=\Delta>$ $\epsilon=\Delta / 2$.

Lemma 2 can be proved under slightly weaker conditions. The joy-of-giving motive need be strictly operative only over a range of $H \in[\underline{H}, \infty)$, where $\underline{H}$ is the amount of the public good that would be provided in the absence of any joy-of-giving motive (Andreoni [1988] has proved that $\underline{H}$ is finite). Adding in a joy-of-giving motive must yield aggregate contributions $H \geq \underline{H}$.

LEMma 3. If the joy-of-giving motive is strictly operative for all levels of the public good and utility is described by assumption 2, then (i) $U_{H H}, U_{H h}$, and $U_{H c}$ converge to zero; (ii) the convergence rate of $U_{H H}+U_{H h}-U_{H c}$ is the one at which $U_{H H} \rightarrow 0$; and (iii) the convergence rate is faster than $O\left(N^{-1}\right)$.

Proof. The idea of the proof is to note that in the representative donor model the result of lemma $2, \lim _{N \rightarrow \infty} h_{i}^{*}(N) \geq \underline{h}>0$, implies that $\lim _{N \rightarrow \infty} H^{*}(N)=\infty$. Then concavity establishes parts $\mathrm{i}$ and ii of the lemma. First write

$$
U_{H}\left(x_{i}-h_{i}, H, h_{i}\right)-U_{H}\left(x_{i}-h_{i}, h_{i}, h_{i}\right)=\int_{h_{i}}^{H} U_{H H}\left(x_{i}-h_{i}, w, h_{i}\right) d w .
$$


The left-hand side is a finite negative number. This can be seen by noting that part $\mathrm{i}$ of assumption $2 \mathrm{~b}$ and concavity imply $U_{H}\left(x_{i}-h_{i}, h_{i}, h_{i}\right) \geq U_{H}\left(x_{i}-h_{i}\right.$, $\left.H, h_{i}\right)>0$ for all $H \geq h_{i}$ and that $U_{H}\left(x_{i}-h_{i}, h_{i}, h_{i}\right)$ is finite (assumption 2c). Hence, the integral $\int_{h_{i}}^{\infty} U_{H}\left(x_{i}-h_{i}, w, h_{i}\right) d w$ must be finite as $H \rightarrow \infty$. Because concavity requires $U_{H H}(\cdot, H, \cdot) \leq 0$ for all $H$, this integral can converge only if $\lim _{H \rightarrow \infty} U_{H H}=0$. We can state this result as $U_{H H}=O\left(N^{\phi}\right)$, where $\phi<0$ is the convergence rate of $U_{H H}$.

Concavity also requires positive second principle minors; in particular, $U_{c c} U_{H H}-\left(U_{H c}\right)^{2} \geq 0$. The first term is positive and in the limit converges to zero because $U_{H H}$ is converging to zero and $U_{c c}$ is finite (if $U_{c c}$ was $-\infty$, then $U_{c}$ would become negative in violation of part ii of assumption $2 \mathrm{~b}$ ). Hence, to satisfy this second principle minor condition in the limit, $U_{H c}$ must converge to zero and at a rate faster than $U_{H H}$. That is, $U_{H c}=O\left(N^{\chi}\right)$, where $\chi \leq \phi<0$. A similar argument establishes $U_{H h}=O\left(N^{\psi}\right)$, where $\psi \leq \phi<0$. Together these results produce $U_{H H}+U_{h h}-U_{H c}=O\left(N^{\phi}\right)$. Parts i and ii of the lemma are established.

It remains to be shown that $\phi<-1$ (faster than rate $N$ convergence). We shall assume the opposite and show that this contradicts the previous result that the integral in (A5) is finite. To begin, we write a lower bound for the (negative) of that integral:

$$
\begin{gathered}
\int_{h_{i}^{*}(N)}^{H^{*}(N)}-U_{H H}\left(x_{i}-h_{i}^{*}(N), w, h_{i}^{*}(N)\right) d w \\
\geq \sum_{k=1}^{N}-U_{H H}\left(\cdot, H^{*}(k), \cdot\right)\left[H^{*}(k)-H^{*}(k-1)\right] \\
\geq \underline{h}(N) \sum_{k=1}^{N}-U_{H H}\left(\cdot, H^{*}(k), \cdot\right),
\end{gathered}
$$

where $\underline{h}(N) \equiv \min _{k}\left[H^{*}(k)-H^{*}(k-1)\right]$, which is finite and bounded away from zero in the limit (lemma 2).

Consider the sequence $-U_{H H}(k)$ and the series $\Sigma-U_{H H}(k)$, where we have suppressed explicit reference to $H^{*}(k)$. We know that $-U_{H H}(k)=O\left(k^{\phi}\right)$, where $\phi<0$, but now assume $\phi \geq-1$. Then there exists a number $s,-1 \leq s \leq \phi<0$, such that the sequence $k^{s}$ converges to zero faster than $-U_{H H}(k)$ but slower than $O\left(k^{-1}\right)$; that is, $\lim _{k \rightarrow \infty}\left[k^{s} /-U_{H H}(k)\right]=0$. Then by the limit comparison test, if $\sum k^{s}$ diverges, which it does in this case because $s \geq-1$, then $\sum-U_{H H}(k)$ diverges. Then (A6) implies that the left-hand side integral diverges and the contradiction is achieved. Q.E.D.

Proposition 2 follows from part iii of corollary 1.1 and lemmas 1-3. Q.E.D. 


\section{Appendix B}

TABLE B1

Organizations in Analysis and Average Private Contributions from 1987 to 1992

\begin{tabular}{|c|c|}
\hline Organization & Contributions \\
\hline Accion Internat. & 1.07 \\
\hline Adventist Development and Relief Agency Internat. & 11.34 \\
\hline African Medical and Research Found. & .76 \\
\hline African Methodist Episcopal Church Service and Development Agency & .13 \\
\hline African-American Inst. & 1.16 \\
\hline African-American Labor Center & .24 \\
\hline Africare & 5.37 \\
\hline AFS Intercultural Programs* & 3.60 \\
\hline Aga Khan Found., USA & 2.95 \\
\hline Agricultural Cooperative Development Internat. & .25 \\
\hline Aid to Artisans & .21 \\
\hline Air Serv Internat. & .36 \\
\hline ALM Internat. & 8.35 \\
\hline America's Development Found. & .49 \\
\hline America-Mideast Educational and Training Services & 1.12 \\
\hline American Dentists for Foreign Service & .34 \\
\hline American Inst. for Free Labor Development & 2.18 \\
\hline American Jewish Joint Distribution Comm. & 72.87 \\
\hline American Near East Refugee Aid & 1.57 \\
\hline American ORT Federation & 7.53 \\
\hline American Red Magen David for Israel & 6.88 \\
\hline American Refugee Comm. & 1.13 \\
\hline AmeriCares Found.* & 61.71 \\
\hline Andean Rural Health Care & .53 \\
\hline Asia Found. & 12.06 \\
\hline Books for the World & .07 \\
\hline Brother's Brother Found.* & 48.44 \\
\hline Catholic Near East Welfare Assoc. & 15.87 \\
\hline Catholic Relief Services-USCC** & 59.29 \\
\hline Center to Prevent Childhood Malnutrition & .26 \\
\hline Centre for Development and Population Activities & .98 \\
\hline Children Internat.* & 27.86 \\
\hline Chol-Chol Found. & .17 \\
\hline Christian Children's Fund* & 97.00 \\
\hline Compassion Internat.* & 39.27 \\
\hline Conservation Internat. Found. & 12.26 \\
\hline Cooperative for American Relief Everywhere* & 88.88 \\
\hline Coordination in Development & 1.07 \\
\hline Found. for Peoples of the South Pacific/Counterpart Found. & .63 \\
\hline Dental Health Internat. & .09 \\
\hline Direct Relief Internat. & 10.99 \\
\hline Esperanca & 1.62 \\
\hline Family Health Internat. & .71 \\
\hline Florida Assoc. of Voluntary Agencies for Caribbean Action & .27 \\
\hline Food for the Hungry* & 23.41 \\
\hline Food for the Poor & 7.79 \\
\hline Found. for Internat. Community Assistance & .37 \\
\hline Friends of the Shanta Bhawan & .04 \\
\hline Global Health Action & .69 \\
\hline Global Hunger Project & 8.33 \\
\hline Hadassah, the Women's Zionist Org. of America* & 63.72 \\
\hline
\end{tabular}


TABLE B1

(Continued)

\begin{tabular}{|c|c|}
\hline Organization & $\overline{\text { Contributions }}$ \\
\hline Health Volunteers Overseas & 2.77 \\
\hline Helen Keller Internat. & 3.18 \\
\hline Indus. Medical Found. & .37 \\
\hline Inst. for Development Research & 23 \\
\hline Inst. of Internat. Education & 87.32 \\
\hline Interchurch Medical Assistance & 16.65 \\
\hline Internat. Child Care USA & .50 \\
\hline Internat. Executive Service Corps & 25.3 \\
\hline Internat. Eye Found. & 1.74 \\
\hline Internat. Inst. of Rural Reconstruction & 1.11 \\
\hline Internat. Lifeline & 1.47 \\
\hline \multicolumn{2}{|l|}{ Internat. Planned Parenthood Federation, Western Hemisphere } \\
\hline Region & 4.39 \\
\hline Internat. Rescue Comm.* & 9.81 \\
\hline Internat. Voluntary Services & .88 \\
\hline Katalysis North/South Development Partnership & .32 \\
\hline Lions Club Internat. Found. & 16.12 \\
\hline Lutheran World Relief & 17.89 \\
\hline MAP Internat.* & 43.28 \\
\hline Medical Teams Internat. & 5.20 \\
\hline Mennonite Central Comm.* & 26.58 \\
\hline Mercy Corps Internat.* & 10.95 \\
\hline Mercy Ships & 6.44 \\
\hline Minnesota Internat. Health Volunteers & .15 \\
\hline National Cooperative Business Assoc. & .05 \\
\hline Near East Found. & .65 \\
\hline New Israel Fund & 6.05 \\
\hline OBOR & .07 \\
\hline Operation Bootstrap Africa & .20 \\
\hline Opportunities Industrialization Centers Internat. & 1.11 \\
\hline Opportunity Internat. & 1.87 \\
\hline Our Little Brothers and Sisters & 5.99 \\
\hline Outreach Internat. & .79 \\
\hline Pan American Development Found. & 5.88 \\
\hline Partners of the Americas & 1.89 \\
\hline Pathfinder Internat. & 1.82 \\
\hline Pearl S. Buck Found. & 4.28 \\
\hline People-to-People Health Found. & 36.33 \\
\hline Phelps-Stokes Fund & 1.90 \\
\hline Plan Internat. USA* & 28.42 \\
\hline Polish American Congress Charitable Found. & 21.31 \\
\hline Population Services Internat. & .62 \\
\hline Private Agencies Collaborating Together & .29 \\
\hline Program for Appropriate Technology in Health & 4.39 \\
\hline Project Concern Internat. & 6.13 \\
\hline Project ORBIS Internat. & 6.57 \\
\hline Rizal/MacArthur Memorial Found. & .03 \\
\hline Rotary Found. of Rotary Internat.* & 76.12 \\
\hline Salvadoran American Found. & 5.82 \\
\hline Save the Children Federation* & 44.24 \\
\hline Share and Care Found. for India & .88 \\
\hline Sovereign Military Order of Malta, Federal Assoc., U.S.A. & 1.31 \\
\hline Summer Inst. of Linguistics & 74.84 \\
\hline
\end{tabular}


TABLE B1

(Continued)

\begin{tabular}{lr}
\hline \hline Organization & Contributions \\
\hline TechnoServe & 2.36 \\
Thomas A. Dooley Found./INTERMED_USA & .71 \\
Tom Dooley Heritage & .10 \\
Town Affiliation Assoc. of the United States & .49 \\
Trickle-Up Program & .69 \\
United Board for Christian Higher Education in Asia & 1.31 \\
United Palestinian Appeal & .85 \\
United Ukrainian American Relief Comm. & .46 \\
United Way Internat. & 1.02 \\
U.S. Comm. for UNICEF* & 28.39 \\
Volunteers in Overseas Cooperative Assistance & 2.21 \\
Volunteers in Technical Assistance & .52 \\
Winrock Internat. Inst. for Agricultural Development & 5.21 \\
World Concern Development Org. & 12.99 \\
World Education & .76 \\
World Emergency Relief & 7.26 \\
World Learning & 2.46 \\
World Rehabilitation Fund & .69 \\
World Relief Corp. & 7.18 \\
World Resources Inst. & 2.69 \\
World Vision Relief and Development* & 202.30 \\
World Wildlife Fund* & 32.83 \\
\hline
\end{tabular}

NoTE.-Average annual private contributions are reported in millions of constant 1992 dollars.

* Organization appeared in Money's 1992 list of 100 large charities.

\section{References}

$\rightarrow$ Altonji, Joseph G.; Hayashi, Fumio; and Kotlikoff, Laurence J. "Parental Altruism and Inter Vivos Transfers: Theory and Evidence." J.P.E. 105 (December 1997): 1121-66.

$\rightarrow$ Andreoni, James. "Privately Provided Public Goods in a Large Economy: The Limits of Altruism." J. Public Econ. 35 (February 1988): 57-73.

$\rightarrow-$. "Giving with Impure Altruism: Applications to Charity and Ricardian Equivalence." J.P.E. 97 (December 1989): 1447-58.

$\rightarrow$. "Impure Altruism and Donations to Public Goods: A Theory of WarmGlow Giving." Econ. J. 100 (June 1990): 464-77.

$\rightarrow-$. "An Experimental Test of the Public Goods Crowding-Out Hypothesis." A.E.R. 83 (December 1993): 1317-27.

$\rightarrow$ Bergstrom, Theodore; Blume, Lawrence; and Varian, Hal. "On the Private Provision of Public Goods.” J. Public Econ. 29 (February 1986): 25-49.

Biddle, Jeff E. "Religious Organizations." In Who Benefits from the Nonprofit Sector? edited by Charles T. Clotfelter. Chicago: Univ. Chicago Press, 1992.

$\rightarrow$ Bolton, Gary E., and Katok, Elena. "An Experimental Test of the Crowding Out Hypothesis: The Nature of Beneficent Behavior." J. Econ. Behavior and Organization 37 (November 1998): 315-31.

$\rightarrow$ Case, Anne. "Spatial Patterns in Household Demand." Econometrica 59 (July 1991): 953-65.

$\rightarrow$ Cornes, Richard, and Sandler, Todd. "Easy Riders, Joint Production, and Public Goods." Econ. J. 94 (September 1984): 580-98. 
$\rightarrow$ _ "The Comparative Static Properties of the Impure Public Good Model." J. Public Econ. 54 (July 1994): 403-21.

Dasgupta, Dipankar, and Itaya, Jun-ichi. "Comparative Statics for the Private Provision of Public Goods in a Conjectural Variations Model with Heterogeneous Agents." Public Finance 47, no. 1 (1992): 17-31.

$\rightarrow$ Hochman, Harold M., and Rodgers, James D. "Pareto Optimal Redistribution." A.E.R. 59, no. 4, pt. 1 (September 1969): 542-57.

$\rightarrow$ Ihori, Toshihiro. "Impure Public Goods and Transfers in a Three-Agent Model." J. Public Econ. 48 (August 1992): 385-401.

$\rightarrow$ Isaac, R. Mark; Walker, James M.; and Williams, Arlington W. "Group Size and the Voluntary Provision of Public Goods: Experimental Evidence Utilizing Large Groups.” J. Public Econ. 54 (May 1994): 1-36.

Joulfaian, David, and Power, Laura. "Charitable Contributions and Nonprofit Institutions.” Manuscript. Washington: Treasury Dept., Off. Tax Analysis, 1996.

Kaplan, Ann E., ed. Giving USA. New York: American Assoc. Fund-Raising Council, 1993.

$\rightarrow$ Khanna, Jyoti; Posnett, John; and Sandler, Todd. "Charity Donations in the UK: New Evidence Based on Panel Data.” J. Public Econ. 56 (February 1995): 257-72.

$\rightarrow$ Khanna, Jyoti, and Sandler, Todd. "Partners in Giving: The Crowding-In Effects of UK Government Grants.” European Econ. Rev. 44 (August 2000): 1543-56.

$\rightarrow$ Kingma, Bruce Robert. "An Accurate Measurement of the Crowd-Out Effect, Income Effect, and Price Effect for Charitable Contributions.” J.P.E. 97 (October 1989): 1197-1207.

Mulligan, Casey B. Parental Priorities and Economic Inequality. Chicago: Univ. Chicago Press, 1997.

$\rightarrow$ Okten, Cagla, and Weisbrod, Burton A. "Determinants of Donations in Private Nonprofit Markets.” J. Public Econ. 75 (February 2000): 255-72.

$\rightarrow$ Payne, A. Abigail. "Does the Government Crowd-Out Private Donations? New Evidence from a Sample of Non-profit Firms." J. Public Econ. 69 (September 1998): 323-45.

Ribar, David C., and Wilhelm, Mark O. "Charitable Contributions to International Relief and Development.” Nat. Tax J. 48 (June 1995): 229-44.

$\rightarrow$ Roberts, Russell D. "A Positive Model of Private Charity and Public Transfers." J.P.E. 92 (February 1984): 136-48.

- "Crowding-Out with Endogenous Government." Manuscript. St. Louis: Washington Univ., John M. Olin School Bus., 1993.

$\rightarrow$ Rose-Ackerman, Susan. "Charitable Giving and 'Excessive' Fundraising." Q.J.E. 97 (May 1982): 193-212.

—. "Do Government Grants to Charity Reduce Private Donations?" In The Economics of Nonprofit Institutions: Studies in Structure and Policy, edited by Susan Rose-Ackerman. New York: Oxford Univ. Press, 1986.

Salamon, Lester M. "Social Services." In Who Benefits from the Nonprofit Sector? edited by Charles T. Clotfelter. Chicago: Univ. Chicago Press, 1992.

Steinberg, Richard S. "Should Donors Care about Fundraising?” In The Economics of Nonprofit Institutions: Studies in Structure and Policy, edited by Susan RoseAckerman. New York: Oxford Univ. Press, 1986.

$\rightarrow$. "Voluntary Donations and Public Expenditures in a Federalist System." A.E.R. 77 (March 1987): 24-36.

$\rightarrow$ - "Does Government Spending Crowd Out Donations? Interpreting the Evidence." Ann. Public and Cooperative Econ. 62 (October-December 1991): 591-617. 
$\rightarrow$ Sugden, Robert. "On the Economics of Philanthropy." Econ. J. 92 (June 1982): $341-50$.

U.S. Agency for International Development. Voluntary Foreign Aid Programs. Washington: U.S. Agency Internat. Development, 1988-94.

- US PVO Executive Contact List. Washington: U.S. Agency Internat. Development, 1988, 1991, 1992.

$\rightarrow$ Vicary, Simon. "Joint Production and the Private Provision of Public Goods." J. Public Econ. 63 (February 1997): 429-45.

$\rightarrow$ Warr, Peter G. "Pareto Optimal Redistribution and Private Charity." J. Public Econ. 19 (October 1982): 131-38.

$\rightarrow$ - "The Private Provision of a Public Good Is Independent of the Distribution of Income." Econ. Letters 13, nos. 2-3 (1983): 207-11.

$\rightarrow$ White, Halbert. "A Heteroskedasticity-Consistent Covariance Matrix Estimator and a Direct Test for Heteroskedasticity." Econometrica 48 (May 1980): 817-38. 